\title{
Ambivalências da sociedade da informação
}

\section{Pedro Demo}

$\mathrm{PhD}$ em Sociologia, Alemanha, 1967-1971. Professor Titular da UnB, Departamento de Serviço Social. Pós-Doutor pela UCLA, Los Angeles, agosto de 1999 a abril de 2000. Mais de 40 livros nas áreas de política social e metodologia científica.

\begin{abstract}
Resumo
O texto discute a possibilidade da desinformação em processos informativos como componente intrínseco da comunicação humana. Em parte é fenômeno normal, por conta de dupla seletividade: nosso aparato perceptor capta o que lhe é viável captar, e cada sujeito capta de acordo com seus interesses. O problema está sobretudo na manipulação excessiva da informação, provocando efeitos imbecilizantes mais ou menos ostensivos. É o caso do advertising que pretende causar um tipo de influência imperceptível muito efetiva, porque se apóia em estratégias refinadas de conhecimento especializado. É fundamental preservar o ambiente crítico e autocrítico para poder reduzir e controlar a informação.
\end{abstract}

\section{Palavras-chave}

Sociedade da informação; Sociedade do conhecimento; Globalização; Manipulação da informação; Economia da informação.

\section{Ambivalence of the information society}

\begin{abstract}
This text argues the possibility of de-information in informative processes as an intrinsic component of the human communication. Partially it is a normal phenomenon due to double selectivity: our perceptive apparatus picks up what is viable to perceive, and each subject picks up according to his own interests. The problems lies mainly in the excessive manipulation of information, implying more or less ostensive "imbecilizing" effects. It is the case of advertising that pretends to produce a type of very effective non perceived influence, since it is based in refined strategies of expert knowledge. It is fundamental to preserve the critical and self-critical environment in order to be possible to reduce e control the manipulative information.
\end{abstract}

\section{Keywords}

Information society; Knowledge society; Globalization; Information manipulation; Information economy.

\section{INTRODUÇÃO}

Em obra marcante recente, Bauman discute a ambivalência das relações sociais, em suas faces negativas e positivas, permanecendo a impressão de que a vida em sociedade é essencialmente ambígua, como são, ademais, as relações de poder: podemos até encontrar o poder que enobrece, mas é bem mais comum o poder manhoso, dissimulado, que se aproveita da sombra para prosperar ${ }^{1}$. O poder, como bem diria Foucault, se esgueira pelas beiradas, busca não ser percebido para influir tanto mais, procura a obediência do outro sem que este a perceba, inventa privilégio que a vítima pensa ser mérito, usa o melhor conhecimento para imbecilizar ${ }^{2}$. Não seria diferente com a informação: desinformar pode ser seu projeto principal. Não se trata apenas de nos entupir com informação de tal forma que já não a saibamos manejar, mas sobretudo de usá-la para seu oposto, no sentido mais preciso de cultivo da ignorância. Mais que tudo, conhecimento é ambivalente: sempre foi nossa arma mais decisiva da emancipação, mas não o é menos da colonização. $O$ processo atual de globalização aponta para esta direção de modo ostensivo: o que mais se globaliza são formas globalizantes de discriminação. Longe de as chances estarem mais bem distribuídas, concentram-se em clivagens tanto mais drásticas. Neste texto, pretendemos abordar muito preliminarmente o outro lado da sociedade da informação, com o objetivo de alargar o espectro da discussão sobre a importância marcante da informação em nossa sociedade.

\section{SOCIEDADE E ECONOMIA DA INFORMAÇÃO}

Utiliza-se a nomenclatura da "sociedade do conhecimento" praticamente como sinônimo de "sociedade da informação", mesmo que esta última noção contenha, como mostra com grande verve Castells, ainda a perspectiva da "rede" . O conceito de rede está bem mais próximo do campo da informática, apontando ademais para o mundo virtual da rede não física, embora não menos real. Sem rebuscar filigranas conceituais, creio que a problemática se concentra em dois patamares mais visíveis: 
a) de um lado, temos o desenvolvimento sem precedentes do conhecimento como base emancipatória ambígua desta sociedade, provocando condições mais favoráveis de condução autônoma, como bem mostram Böhme/Stehr em sua discussão sobre a "sociedade do conhecimento" : "o que distingue uma sociedade do conhecimento acima de tudo, do ponto de vista de suas precursoras históricas é que se trata de uma sociedade que é, a um nível sem precedentes, o produto de sua própria ação. A balança entre natureza e sociedade, ou entre fatos além do controle dos humanos e aqueles submetidos a seu controle, elevou-se de modo impressionante. Elevou-se mais e mais para as capacidades que são construídas socialmente e permitem que a sociedade opere por si mesma" (p. 19); embora se trate de uma trajetória de emancipação muito ambivalente, por conta dos efeitos colonizadores persistentes, não se pode evitar de reconhecer que a capacidade de condução da história aumentou flagrantemente; o processo galopante de informatização pode ser reconhecido como seu carro-chefe, porque condensa os mais evidentes impactos teóricos e práticos do conhecimento;

b) de outro lado, porém, é mister observar que outra mola mestra comparece à cena, que é a competitividade econômica baseada na produção e uso intensivos de conhecimento, revelando que a dinâmica desta sociedade do conhecimento é feita de modo preponderante pelo mercado neoliberal; em termos teóricos, estaríamos vivendo agora a "mais-valia relativa", como assinalava Marx, fundada em ciência e tecnologia, ou seja, a produtividade econômica é alimentada essencialmente, não mais pela força física do trabalhador, mas por sua inteligência; Marx, sem fazer maiores aprofundamentos sobre a mais-valia relativa, previu que traria consigo repercussões inimagináveis no processo produtivo, embora sem desfazer seu caráter espoliativo ${ }^{5}$; ao contrário, como mostram outros autores, o trabalho duro, em vez de recuar, parece, amplamente, tornar-se ainda mais dramático; enquanto para uma menor parte dos trabalhadores é sempre possível produzir mais e melhor com menos horas trabalhadas, para muitos, sob o efeito da maisvalia, é mister trabalhar ainda mais para obter ou manter os mesmos salários, cuja tendência de decréscimo é geral ${ }^{6}$.

A conjugação da sociedade do conhecimento com a lógica abstrata da mercadoria ${ }^{7}$ parece nítida, como mostra com grande ênfase Aronowitz em sua obra sobre "a fábrica do conhecimento". Analisando as universidades norteamericanas, deplora que tenham abandonado praticamente seu mandato educativo e social, para restringir-se ao atrelamento capitalista, perfazendo o pano de fundo da competitividade sem limites ${ }^{8}$. A criatividade acadêmica estaria em grande parte aprisionada pelo mercado, provocando forte seletividade nos cursos, em desfavor de compromissos históricos com os interesses coletivos da humanidade. Com efeito, o conhecimento mais inovador é provocado pelo mercado, que necessita do ímpeto desconstrutivo do conhecimento, particularmente do conhecimento dito pós-moderno, colocando a inovação mercantilizada como razão maior de ser. Neste sentido, ao falarmos de sociedade da informação ou do conhecimento é fundamental não perder de vista seu contexto econômico, para não supervalorizarmos o aspecto tecnológico, como se a face do progresso fosse a única. Trata-se de novo e sempre no capitalismo de progresso unilateral, extremamente concentrador de renda e poder, como se pode averiguar das grandes fusões de empresas, cujo resultado notável é poder eximir-se, na prática, das "regras" do mercado. Como aponta De Landa, trata-se de um "antimercado", porque se torna dono dele 9 . Apenas as pequenas e médias empresas se submetem, por exemplo, à competição capaz de favorecer ao consumidor, enquanto as grandes literalmente "fazem" os preços. Não por acaso, a grande empresa tem peso residual na produção do emprego.

O pano de fundo capitalista revela que não se trata apenas da "sociedade", mas principalmente da "economia" da informação, que, ademais, facilita enormemente a volatilidade do capital, sem pátria, globalizado ${ }^{10}$. Esta marca estiola as expectativas ingênuas de que a globalização traria benefícios repartidos com todos globalmente. As pretensões "universalizantes" do conhecimento, tão bem expressas na idéia de "universidade", redundaram no aprisionamento ostensivo de suas energias no mercado, assinalando que o efeito redistributivo é, como regra, inverso. O mundo tornou-se uma "pequena aldeia", não tanto porque nos vemos e comunicamos mais facilmente, mas porque as linhas de força se fizeram tanto mais convergentes. A energia mais forte da globalização pareceria ser a "dolarização" de tudo, refazendo a trajetória colonizadora com tanto maior vigor e discriminação. Este reconhecimento não poderia negar as potencialidades extremas aí contidas, como a intercomunicação mais disponível, mas sua ambivalência não é menos flagrante. De uma parte, a interdependência dos povos e pessoas pode repercutir em graus maiores de liberdade, à medida que todos estamos no mesmo barco, mas, de outra, pode produzir amarras ainda mais rígidas, quando sua dinâmica foge ao controle da maioria, concentrando-se, como privilégio extremo, em poucas mãos. Um dos resultados marcantes deste processo de globalização é a situação confortável dos Estados Unidos, que, ao contrário dos outros países centrais, apresenta um horizonte bem mais palatável de inserção no mercado, ainda que se reconheça 
o ritmo decadente dos salários ${ }^{11}$. Enquanto a globalização força todos a alinhamentos drásticos, este impacto parece preservar os Estados Unidos, pela razão simples de que é o centro deste alinhamento. Todos precisam alinhar-se a eles, o que permite comandar confortavelmente tal processo de alinhamento. Em nada mudou o fenômeno da mais-valia, ainda que sua dinâmica esteja marcada por outro momento histórico, no qual a produção e o uso intensivo de conhecimento se tornaram a mola mestra ${ }^{12}$.

\section{INFORMAR PARA DESINFORMAR}

É já comum a queixa de que estamos entupidos de informação, cercados de um bombardeio do qual já não temos qualquer controle. Na verdade, pensamos que se trata de informação, mas na verdade trata-se de manipulação sibilina. Em parte, esta contaminação seria natural, por conta do ambiente ambivalente de todo processo comunicativo. Ao contrário do que Habermas propõe, a ilação estratégica, longe de ser espúria, é constitutiva da comunicação humana. Sobretudo para cientistas sociais é difícil aceitar que o primeiro impulso da fala seja comunicar, não mais que comunicar, porque sabemos que, em sociedade, o contexto do poder é intrínseco, com suas linhas de força, muitas vezes despercebidas, como quer Bourdieu em sua crítica a Habermas. Sem desmerecer que todo contexto comunicativo supõe um pano de fundo não questionado que permite transitar símbolos e semânticas reciprocamente compreensíveis, é preciso levar em conta que a validade do discurso não se restringe a tal contexto, mas se remete ao ambiente social, cuja normatividade não é apenas dada, mas também historicamente construída ${ }^{13}$. O pós-modernismo, por sua vez e desconsiderando aqui seus excessos, não está disposto a aceitar este tipo de kantismo transcendental, que acaba desgarrando a validade de seu leito concreto de facticidade ${ }^{14}$. Sfez, em sua "crítica da comunicação" chega a falar de "mofo kantiano", referindo-se a pretensões de validade transcendental universalista ${ }^{15}$.

Neste sentido, não seria correto falar de "contaminação", porque a ambigüidade é intrínseca ao fenômeno comunicativo, como qualquer hermenêutica atestaria sem maiores problemas: todo processo interpretativo supõe um sujeito culturalmente contextuado. Desinformar faz parte da informação, assim como a sombra faz parte da luz. Trata-se do mesmo fenômeno, apenas com sinais inversos. Estudos sobre a tessitura do conhecimento apontaram freqüentemente para esta característica ambivalente, a começar pela idéia de "conhecimento proibido". Esta noção tão comum na sociedade e em muitos de seus mitos e narrativas religiosas (por exemplo, no Gênesis, o pecado propriamente dito de Adão e Eva foi comer da árvore do conhecimento), aponta para a periculosidade própria do conhecimento: quanto mais inovador, menos bem comportado $^{16}$. Emancipar-se, com efeito, implica capacidade de confronto, quebra da ordem vigente considerada impositiva e injusta, consideração de alternativas. Sua face disruptiva parece evidente, porque conhecer implica intrinsecamente questionar. Sua tendência desconstrutiva é frontal, embora possa ser facilmente dissimulada.

Mas seria ingênuo pensar que a capacidade disruptiva esteja apenas a serviço do bem, como seria grotesco imaginar que a ideologia seja predominantemente "contraideologia" em favor dos oprimidos. A habilidade inovadora do conhecimento não é menor quando motivada por projetos colonizadores. A história poderia facilmente mostrar que a inovação científica se fez sempre sob o impacto preferencial da guerra, destruição, dominação. Se comparássemos a capacidade que temos de fazer guerra com a que temos de fazer paz, teríamos alguma noção de como a primeira está avançada e a segunda absurdamente atrasada. É sempre possível, pois, usar o melhor conhecimento para construir o mais refinado processo de imbecilização. Desinformar será, portanto, parte fundamental do processo de informação. Em parte este resultado é comum, porque, quando construímos a informação, procedemos seletivamente perante um cabedal por vezes transbordante disponível de dados, ou seja, selecionamos o que é possível captar, sem falar que preferimos o que nos interessa. Há, pois, dois vetores seletivos no fundo muito naturais: como mostra a biologia, nosso aparato perceptor não capta tudo, mas o que é possível captar, dentro de seu trajeto evolucionário; nossos olhos não vêem tudo, mas o que conseguem ver ${ }^{17}$; ademais, entram em cena nossos interesses, através dos quais a interpretação ganha forros claros de politicidade inegáve ${ }^{18}$. Como asseveram Maturana e Varela, a percepção está condicionada ao "ponto de vista do observador", o que nos faz, ademais, prisioneiros de nossas próprias descrições ${ }^{19}$.

Entretanto, a questão mais dura refere-se ao processo manipulativo por vezes ostensivo que a sociedade da informação nos impinge. Basta olha para a lógica do advertising: seu objetivo é claramente manipular nossas motivações, atingindo de preferência níveis subliminares. Somos levados a comportamentos atrelados sob a expectativa de que estamos exercendo nossa liberdade mais criativa ${ }^{20}$. Rushkoff, em tom irritado, pergunta-se por que acreditamos nisso tudo de maneira tão inocente, 
se o pano de fundo é de nítida coerção ${ }^{21}$. $O$ problema é que se trata de coerção muito bem construída, tão bem que não se percebe como tal. Algo similar pode-se dizer do marketing, que representa estratégias inteligentes de convencimento sub-reptício, armadas com refinados processos de informação dirigida ${ }^{22}$. Vivemos numa época em que o marketing se tornou cultura e a cultura marketing, enredando-se no mesmo novelo, dificultando extremamente o surgimento de contraculturas. Há ainda a queixa constante contra a invasão da privacidade, tornando tudo informação devassada, como é o caso já público e notório das câmaras eletrônicas de controle, supostamente para fins de segurança. Pode haver o lado da transparência, como quer Brin, mas dificilmente não predomina o lado da prepotência manipulativa ${ }^{23}$.

O problema da informação manipulativa, contudo, não deveria nos perturbar em demasia, porque lhe faz parte. Quando nos surpreendemos com efeitos manipuladores dos noticiários da televisão, por exemplo, damos um atestado de incrível ingenuidade, porque é impraticável informar com imparcialidade completa. No fundo, adotamos a postura representacionista do conhecimento, segundo a qual retrata-se a realidade assim como ela, como num espelho refletor. Este tipo de epistemologia está abalado, porque a própria biologia mostra que o cérebro humano não é máquina instrucionista que funciona apenas por algoritmos e instruções precisas, mas aparato selecionista evolucionário capaz de lidar com a ambigüidade de modo tipicamente reconstrutivo. Como mostram com grande detalhe Edelman/Tononi, o processo evolucionário, que se realiza no tempo longo, não se restringe a relações lógicas, dadas, sempre recorrentes, mas admite variabilidade criativa nítida, o que permitiu fazer emergir a vida a partir da matéria, e, no mundo vivo, surgir algo tão complexo e não linear como o cérebro humano ${ }^{24}$. Esta habilidade nos permite, por exemplo, compreender a partir do contexto, manejar panos de fundo implícitos, distinguir duplos sentidos, porque somos capazes de ir além da sintaxe, atingindo o nível semântico. Entretanto, esta fineza de compreensão não se restringe aos bons usos. Vale igualmente para a "arte" de manipular.

Em certo sentido, todo processo informativo é manipulador, porque seleciona a informação disponível, além de a interpretar hermeneuticamente. Esta é marca do conhecimento como tal: à medida que conhece a realidade, destaca nela o que o método pode captar, além de impingir interpretações orientadas pelo interesse, por vezes escuso. Como não é possível fugir da manipulação, o que de melhor conseguimos até hoje é montar estratégias abertas de controle, sabendo que controle total é impraticável, sobretudo indesejável. A contrainterpretação é o corretivo da interpretação, sempre sob risco, assim como a coerência da crítica está na autocrítica. Destarte, a manipulação menos prejudicial é aquela que se oferece à discussão aberta. Falando, por exemplo, de noticiários da televisão, alguns diriam que o "Jornal Nacional" da Globo tende a ser "oficial", no sentido de veicular o que favorece a ordem vigente. A seletividade manipulativa da informação aparece na ênfase sobre notícias favoráveis ao status quo, bem como na maneira de arrumar as notícias e na retórica e estética que as cercam, em particular nos locutores e efeitos especiais. É imbecilizante no sentido de que nos tolhe a visão crítica, fazendo-nos crer que a maneira mais atraente de dar notícia é a própria. Desfaz seu caráter disruptivo, induzindo-nos à acomodação. Outros noticiários também são manipulativos, por certo, mas podem, em seu contraponto, conclamar algo de espírito crítico e, quando menos, não ser tão manipulativos. No pano de fundo de todos, tremula a bandeira certa do mercado: notícia de verdade é aquela que vende.

Se olharmos do ponto de vista da ideologia e a tomarmos como proposta de justificação de relações de poder, a informação, pelo menos em nível considerável, está a seu serviço. No quadro social, a informação nunca aparece apenas como algo "informativo", mas como tática de influência privilegiada. Os que fazem a contra-informação, por sua vez, não deixam de manipular, mas podem manipular menos ou no mínimo praticar a "standpoint epistemololgy", ou seja, tentar perceber a realidade do ponto de vista da vítima ${ }^{25}$. Assumir o ponto de vista do excluído é sempre tarefa complexa, porque inegavelmente continuamos interpretando subjetivamente. A rigor, falar pelo excluído é interpretá-lo, de certo modo "fazê-lo dizer". Por mais que a contra-ideologia se esforce por expressar os anseios dos outros, também é ideologia, ou seja, está mais interessada em justificar relações de poder, do que propriamente "argumentar". Neste sentido, cabe aceitar, com alguma dor, que a manipulação mais aceitável é aquela que, primeiro, não tem receio de assim se aceitar, e que, segundo, sabendo disso, a refreia autocriticamente.

Dito isto, cabe fazer a crítica contra o caráter excessivamente manipulativo da informação hoje. Primeiro, a sociedade continua bastante "desinformada", seja porque lhe chega tendencialmente informação residual, ou porque se lhe impõe informação oficial, ou porque se entope atabalhoadamente. Segundo, há informação de classe superior e inferior, cuja variação está em função como regra do poder aquisitivo de cada um. Alguém que pode assinar vários jornais e revistas tem, 
relativamente, melhores condições de comparar as diferentes fontes e cultivar um pouco mais de espírito crítico. Terceiro, abunda na praça informação imbecilizante, seja por conta da distorção por vezes clamorosa, mas igualmente pela exploração das futilidades da mídia, como são publicações que nada mais fazem do que esticar a mediocridade das novelas mostradas na televisão diariamente. A população, além de "ler" pouco, tende a ler banalidades, que, a título de passatempo, embotam o espírito crítico. Quarto, a mídia está muito distante de sua função pública, porque corresponde a um estilo afrontoso de apropriação privada, dirigida por trâmites comerciais estritos. Não existe qualquer controle público digno de nota que preserve os interesses do público. Sem recair na "censura", sempre impertinente e no fundo equivocada, é preciso que a sociedade possa pressionar adequadamente a mídia, para que os interesses comerciais não sejam os únicos. Quinto, a potencialidade informativa dos novos meios de comunicação está ainda presa a acessos elitistas, e quando traduzida em teleducação, tende fortemente ao instrucionismo ${ }^{26}$. Como bem mostra igualmente a biologia, o instrucionismo é intrinsecamente imbecilizante.

\section{PARA CONCLUIR}

A inteligência está na habilidade de lidar com a ambivalência. Aprender é sobretudo saber pensar, para além da lógica retilínea e evidente, porque nem o conhecimento é reto, nem a vida é caminho linear ${ }^{27}$. Saber criar depende, em grande parte, da capacidade de navegar em águas turvas, saltar onde menos se espera, vislumbrar para além do que é recorrente. A informação não pode ser receita pronta, mas o desafio de a criar, mudar, refazer. $\mathrm{O}$ risco de manipulação é intrínseco, mas é no risco que podemos reduzir a manipulação. A sociedade da informação informa bem menos do que se imagina, assim como a globalização engloba as pessoas e povos bem menos do que se pretende. $\mathrm{Na}$ sociedade da mercadoria, mercadoria vem antes.

A informação é em si ambivalente, tanto em quem a pronuncia, quanto em quem a recebe. Em todos os momentos passa pelo filtro da subjetividade, além de sua dimensão estar limitada pelo aparato perceptor e conceitualizador. Mas é esta ambivalência que resgata sempre a possibilidade de criar, inventar. Se tudo fosse apenas lógico, seria apenas repetitivo. $\mathrm{O}$ mundo da informação é agitado, conturbado, porque é, ao mesmo tempo, intrinsecamente manipulado e impossível de ser totalmente manipulado.

\section{REFERÊNCIAS BIBLIOGRÁFICAS}

1. ANTUNES, R. Os sentidos do trabalho: ensaio sobre a afirmação e a negação do trabalho. São Paulo : Bomtempo, 2000.

2. ARANTES, O., VAINER, C., MARICATO, E. A cidade do pensamento único: desmanchando consensos. Petrópolis : Vozes, 2000.

3. ARONOWITZ, S. The knowledge factory: dismantling the corporate university and creating true higher learning. Boston : Beacon, 2000.

4. BARNES, J. Capitalism's world disorder: working-class politics at the millennium. New York : Pathfinder, 1999.

5. BAUMAN, Z. Modernidade e ambivalência. Rio de Janeiro : Jorge Zahar Editor, 1999.

6. BÖHME, G., STEHR, N. The knowledge society: the growing impact of scientific knowledge on social relations. Boston : D. Reidel, 1986.

7. BOURDIEU, P. A economia das trocas lingüísticas. São Paulo : EDUSP, 1996.

8. BOURDIEU, P. Razões práticas: sobre a teoria da ação. Campinas : Papirus, 1996.

9. BRIN, D. The transparent society: will technology force us to choose between privacy and freedom? Reading : Perseus Books, 1998.

10. CASTELLS, M. The power of identity - the information age: economy, society and culture. Oxford : Blackwell, 1997. v. 2.

11. CASTELLS, M. The rise of the network society - the information age: economy, society and culture. Oxford : Blackwell, 1997. v. 1.

12. CASTELLS, M. 1998. End of millenium - the information age: economy, society and culture. Malden : Blackwell, 1998. v. 3.

13. DE LANDA, M. A thousand years of nonlinear history. New York : Swerve, 1997.

14. DEMO, P. Charme da exclusão social. Campinas : Autores Associados, 1998.

15. DEMO, P. Conhecimento moderno: sobre ética e intervenção do conhecimento. 2.ed. Petrópolis : Vozes, 1999.

16. DEMO, P. Questões para a teleducação. 2. ed. Petrópolis : Vozes, 1999.

17. DEMO, P. Certeza da incerteza: ambivalências do conhecimento e da vida. Brasília : Plano, 2000.

18. DEMO, P. Metodologia do conhecimento científico. São Paulo : Atlas, 2000.

19. EDELMAN, G.M., TONONI, G. A universe of consciousness: how matter becomes imagination. New York : Basic Books, 2000.

20. FERRÉS, J. Televisão subliminar: socializando através de comunicações despercebidas. Porto Alegre : Artmed, 1998.

21. FIORI, J. L. Os moedeiros falsos. Petrópolis : Vozes, 1997.

22. HABERMAS, J. Direito e democracia entre facticidade e validade I. Rio de Janeiro : Tempo Brasileiro, 1997.

23. HABERMAS, J. Direito e democracia entre facticidade e validade II. Rio de Janeiro : Tempo Brasileiro, 1997.

24. HARDING, S. Is science multicultural? Postcolonialisms, feminisms, and epistemologies Bloomington : Indiana University, 1998.

25. KELLY, K. New rules for the new economy: radical strategies for a connected world. London : Penguin Books, 1998. 


\section{Pedro Demo}

26. KIM, J.Y. et alii (Ed.). Dying for growth: global inequality and the health of the poor. Monroe : Common Courage, 2000.

27. NORRETRANDERS, T. The user illusion: cutting consciousness down to size. New York : Penguin Books, 1998.

28. PORTOCARRERO, V. (Org.). Filosofia, história e sociologia das ciências: abordagens contemporâneas. Rio de Janeiro : FIOCRUZ, 1994.

29. RESCHER, N. Forbidden fnowledge and other essays of the pholosophy of cognition. Dordrecht : D. Reidl, 1987. (Episteme, v. 13).

30. RIVERA, F.J.U. Agir comunicativo e planejamento social: uma crítica ao enfoque estratégico. Rio de Janeiro : Fiocruz, 1995.
31. RUSHKOFF, D. Coercion: why we listen to what "they" say. New York : Riverhead Books, 1999.

32. SEABROOK, J. Nobrow the culture of marketing: the marketing of culture. New York: Alfred A. Knopf, 2000.

33. SFEZ, L. Crítica da comunicação. São Paulo: Loyola, 1994.

34. SHATTUCK, R. Forbidden knowledge: from prometeus to pornography. New York : St. Martin's, 1996.

35. VARELA, F.J. et alii. The embodied mind: cognitive science and human experience. Cambridge : MIT, 1997. 